\title{
Design of seedling transplanting machine based on motion controller
}

\author{
Gui-Zhi ZHAO ${ }^{1, a}$, Da-Peng LIU ${ }^{2, b}$ \\ ${ }^{1}$ Inner Mongolia University for the Nationalities, College of Mechanical Engineering, Tong Liao, \\ 028000, China; \\ ${ }^{2}$ NO.724 Research Institute under CSIC, Nanjing Jiangsu 210003, China; \\ aguizhi_84@yahoo.com.cn, 'liudapeng@163.com,
}

Keywords: Seedling transplanting machine, Motion controller, Control system.

\begin{abstract}
In view of the current large labor intensity of seedling transplanting, low efficiency, unable to complete the task on time of transplanting and other issues, a kind of automatic seedling transplanting machine is designed based on motion controller. The seedling transplanting machine control system adopts motion controller as the core, with double CPU structure of "PC + motion controller", which can ensure the system response speed and processing speed. The test proves that the seedling transplanting machine can realize the automatic transplanting process, improve transplanting efficiency, and reduce the cost of transplanting, it has a certain practical significance.
\end{abstract}

\section{Introduction}

A growing world population makes the demand for the amount of agricultural products such as fruits and vegetables increase correspondingly, the countries all over the world are paying more and more attention to the development of agriculture [1]. China is the world's large agricultural country, with the deepening of the adjustment of agricultural industrial structure of China, the export volume of various types of agricultural products is also increasing, and puts forward the new request to the development of agriculture, it will gradually develop in the direction of large area centralized crops [2]. In the production process, the seedling transplanting is a commonly used means of agricultural operation, it can increase the distance between seedlings, the seedlings have enough space to grow, the new set of seedbed has the advantages of soil fertility and nutrient rich. When the seedlings problems arise, the management can separate from the other, which will not affect the growth of the seedlings. So the seedlings has many advantages, it is one of the development direction of agriculture [3]. Long term since, in our country, breeding, ditching, transplanting, soil covering the whole process still relies on the manual labor, labor intensity is high, efficiency of transplanting is low. In the seedlings stage, it is also busy period, labor cannot ensure the completion of transplanting on time [4]. In order to improve the situation, the mechanical formation of seedling transplanting becomes the direction of the seedlings [5]. In this paper, according to the seedlings present situation, a kind of seedling transplanting machine has designed based on motion controller, which can realize the automatic transplanting machine drilling, picking seedling, seedling, soil covering the entire seedling transplanting process. Using the motion controller as the core of the control system can improve the response speed of the system, and guarantee the reliability of the system [6]. It has a certain practical significance to the development of the transplanting seedlings.

\section{Hardware design}

Overall design. As shown in Figure 1, the transplanting machine is mainly composed of ditching mechanism, seedling feeding mechanism, seedling fetching mechanism, seedling holding mechanism, seedling planting mechanism, covering mechanism, wheels and frame etc. The seedling feeding mechanism, seedling fetching mechanism, seedling holding mechanism, seedling planting mechanism are the main part, when at work, plant seedlings is on the transmission belt of seedling feeding mechanism in advance, conveyor belt drives the seedlings to move forward, when seedlings expose to the proximity switch, seedling fetching mechanism clamps the seedling to seedling holding 
mechanism, when reaching the set spacing in the rows, seedling planting mechanism catches seedlings from seedling holding mechanism, and places into the ditch dug by ditching mechanism, covering mechanism will cover it, then the next cycle begins.

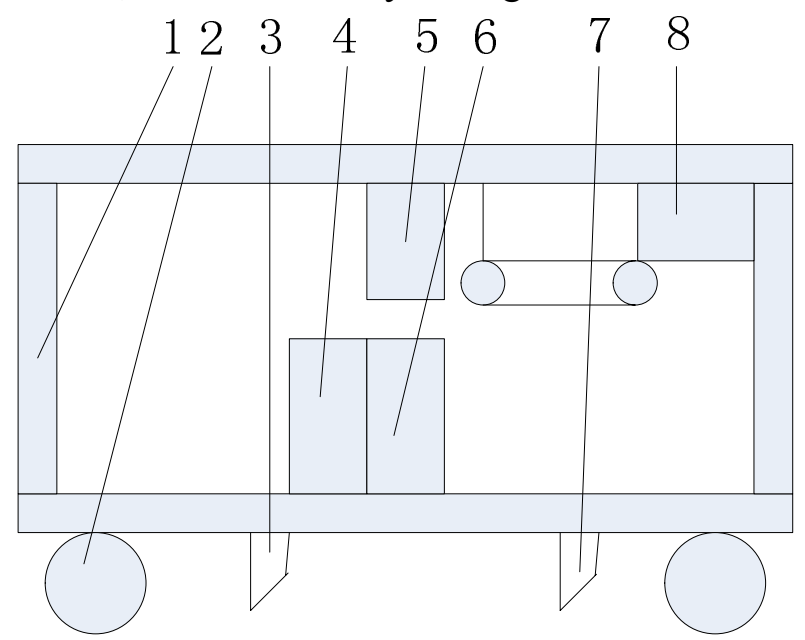

1.Frame 2.Wheels 3. Ditching mechanism 4. Seedling planting mechanism

5. Seedling fetching mechanism 6.Seedling holding mechanism 7. Covering mechanism 8. Seedling feeding mechanism

Figure 1.The transplanting machine schematic diagram

Control system design. Transplanting machine works outdoor in most cases, there may be a lot of electromagnetic interference, so the requirements of transplanting machine are the environment adaptability, good anti-jamming performance, in order to do accurately transplanting, the processor speed must be ensured. Transplanting machine control system in this paper is designed based on the motion controller, motion controller is the core of the whole control system, transplanting machine control system hardware adopts modular design. The motion controller serves as the processor module, motor serves as executing module, each sensor serves as acquisition module, and a man-machine interaction module is also needed. System programming is on the PC. The motion controller and other hardware integration is shown in figure 2.

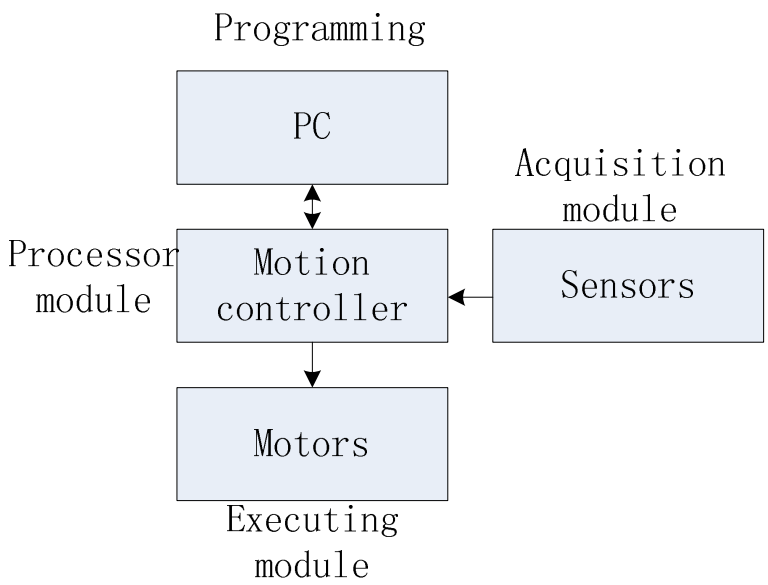

Figure 2.The hardware integration

\section{Software design}

Software structure design. Because the motion controller does not have the program development environment, operation of motion controller is based on PC, it does not have the ability to separate programming, program development also needs to be completed by the computer. So in this paper software structure adopts upper and lower computer structure, motion controller $+\mathrm{PC}$, double CPU. The software structure design in this paper is shown in figure 3, PC machine as the upper 
computer is used for system programming and management, parameter setting and human-computer interaction; motion controller as lower computer is used to perform motion control procedures, control each institution in accordance with the specified size for motion planning road. The motion controller does not have the development environment, but has running environment, motion controller programming is through the upper computer, the program will be transmitted to the motion controller, then the program can be run independently from the upper computer. This way can improve the response speed of the system, ensure the control precision.

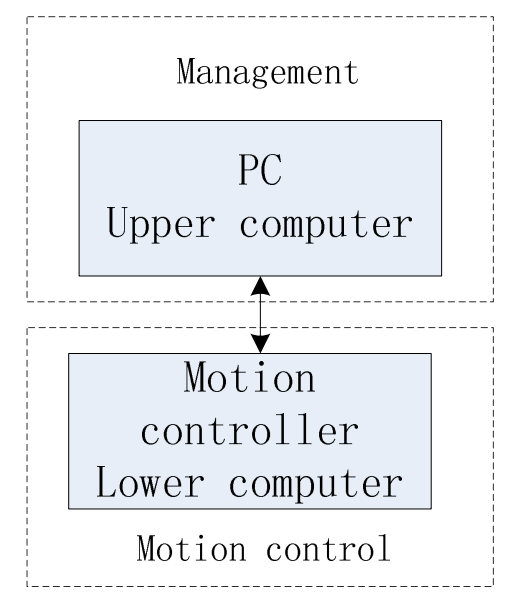

Figure3. Software structure

Program flow design. According to the control requirements of transplanting machine, the program flow of the control system is shown in figure 4. Program initialization is before starting work, the control system will detect whether there are seedlings on seedling feeding mechanism, if the system does not detect the seedlings, the conveyor belt will not begin to work. When the system detects seedlings on the seedlings feeding mechanism, conveyor belt begins to work, drives plant seedlings forward. Seedlings arrives at the designated location, and they are access to the proximity switch, seedling fetching mechanism clamps the seedling to seedling holding mechanism, when they arrive at the setting area, seedling planting mechanism will plant the seedlings from the seedling holding mechanism. The system will automatically detect any fault, if there is failure, it will stop running, and automatically returns to the initialization program.

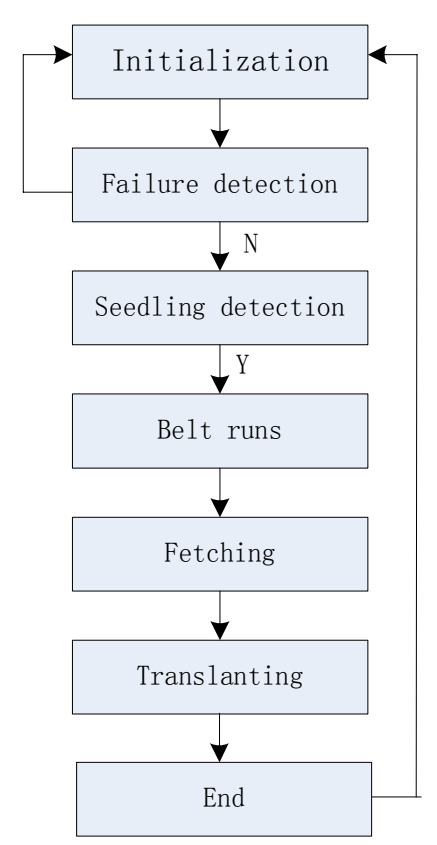

Figure4. Work flow 
I/O design. System receives and sends signals through the $\mathrm{I} / \mathrm{O}$ interface of motion controller, each of them is done by $\mathrm{I} / \mathrm{O}$, the system $\mathrm{I} / \mathrm{O}$ design is as shown in table 1.

Table1. System I/O design

\begin{tabular}{cccc}
\hline & Input & Output \\
\hline IN0 & $\begin{array}{c}\text { The seedling } \\
\text { fetching } \\
\text { photoelectric } \\
\text { switch } \\
\text { The seedling } \\
\text { holding } \\
\text { photoelectric } \\
\text { switch } \\
\text { The seedling } \\
\text { planting } \\
\text { photoelectric } \\
\text { switch }\end{array}$ & OUT1 & The indicator light \\
& OUT2 & The indicator light \\
& & 3 \\
& OUT3 & The indicator light \\
& OUT4 & The indicator light \\
& & 5 \\
\hline
\end{tabular}

\section{Transplanting experiment}

After transplanting machine designed, the transplanting experiment is conducted in the experimental field, the result proves that the transplanting machine can realize the automation ditching, seedling fetching, seedling transplanting, and soil covering the whole transplanting process, the transplanting machine has the advantages of high efficiency, and fast system response. The use of plant seedlings transplanting machine can increase efficiency by more than $50 \%$, which can not only improve the efficiency of transplanting, but also can the liberate the labor force, and reduce the cost of transplanting, which has an important significance.

\section{Summary}

In this paper, aiming at the artificial transplanting seedlings of large labor intensity, low efficiency of transplanting, unable to complete the task on time of transplanting and other issues, a kind of automatic transplanting machine is designed based on motion controller, which can realize the automation ditching, seedling fetching, seedling transplanting, and soil covering the whole transplanting process. The use of double CPU structure of PC + motion controller can improve the system's response speed and processing speed. In the experimental fields, transplanting test is done, the result proves that the transplanting machine is feasible, it can improve the efficiency of transplanting, and reduce the cost, it has a certain practical value.

\section{References}

[1] Ke Bingsheng. International agricultural environment and agricultural development in China [J]. Problem of agricultural economy, 2000, 21 (2): 5-10.

[2] Chen Qifeng. On the reform and development of agriculture in Fujian Chinese [J]. Journal of Kasetsart University: Social Science Edition, 2001, 4 (2): 1-8.

[3] Han Bing, Zhang Yuanxia. The yew seedling transplanting technology [J]. Liaoning forestry science and technology, 2003, (2): 46-46. 
[4] He Hongfei. Jujube seedlings transplanting [J]. Well-off life, 2002, (2): 11-11.

[5] Xiao Mingtao, Sun Songlin, Wang Jinkui. design and test of small seedling transplanting machine [J]. Agricultural Research, 2014, (11).

[6] Wu Hong, Jiang Shilong, Gong Xiaoyun. Current situation and development of motion controller [J]. Manufacturing technology and machine tool, 2004, (1): 24-27. 